groups. The reasons for the relative clemency of social attitudes might be given greater consideration. Comparisons of New Zealand with similar societies might be worth exploring. Although nothing is said here about women, readers should know that another scholar is currently producing a history of lesbian New Zealand.

Brickell's book is one of the finest studies available on the history of homosexuality in a particular country. A beautifully written text with engaging pictures, personal stories and convincing analysis complement each other. This survey of Kiwi 'mates \& lovers' provides an important contribution both to New Zealand history and to the history of sexuality.

Robert Aldrich

University of Sydney, Australia

\title{
Kimberly B. Dugan, The Struggle Over Gay, Lesbian, and Bisexual Rights. Facing Off in Cincinnati. New York and London: Routledge, 2005. I 50 pp. ISBN 0-4I5-97233-7. £50.00.
}

Analyzing two contentious social movements in Cincinnati, Ohio, Dugan generates powerful insights about the influence of cultural variables and interdependent dynamics in mobilization, strategies and outcomes. The context is the backlash of lesbian, gay and bisexual rights (LGB) in 1993 with the approval of Issue 3, an amendment to the City Charter eradicating the legal protection of LGB people against discrimination and refusing the right to recognition as a group. This clause counteracted a previously approved Human Rights Ordinance, interpreted by many as a major breakthrough for LGB rights.

The three-month campaign around Issue 3 constituted the scenario in which Dugan's analysis took place, highlighting the various strategies of the Christian Right (proponent) and the LGB movement (opponent), and their different outcomes. This research was based on qualitative data, including interviews to 24 key informants on both sides, collecting materials produced before and during the campaign, print and visual media analysis, as well as examining organizational documents, such as newsletters, magazines and reports.

Researching the past of these opposing movements, Dugan demonstrates that each of them had already constructed their public image; both movements were known for their ability to mobilize around/against sex politics and accomplish their goals. On one hand, during the 1980s the Christian Right became actively involved in anti-pornography wars. This launched the seeds of new conservative organizations and groups - mostly gathered under the label 'pro-family' - which proved to be crucial in the Issue 3 campaign. On the other hand, the LGB movement had achieved several victories during the early 1990s, especially with the approval of the Equal Employment Opportunities policy in 1991, and the Human Rights Ordinance in 1992, both of which constituted fundamental antidiscrimination measures. In fact, these two initiatives were seen by the conservatives as a sign of the LGB expansion towards affirmative action and special rights, which only Issue 3 could overturn - hence the conservative slogan 'Equal Rights, Not Special Rights'. 
After exploring several theoretical perspectives around social movements and countermovements, the author makes clear that her epistemological background for writing this book lays on cultural analysis, based on frames: 'Simply put, the process of framing is a movement strategy where movements attempt to 'package' their claims and 'sell' them to particular audiences who maintain some control of producing the required policy outcome' (p. 19). Dugan considers three frames injustice, agency and identity - examining the ways these frames were constructed by the two opposing movements.

In contentious politics, movements and countermovements compete for the space provided by key gatekeepers, such as the media. In this process, according to Dugan, the Christian Right was more effective both in the content of messages it launched and in the way it occupied any available public (virtual or physical) space. The point made here is that successful outcomes directly depend not only on existing opportunities but also on adaptive strategies based on actors' interpretations of those same opportunities: 'Changes in the cultural and political landscape are subject to the movement's interpretations and perspective. Thus, political and cultural changes are interpreted by such movements as opportunities or constraints to mobilization' (p. 44). In this respect, Dugan's book suggests a challenging way of studying social movements, anchored on their dynamic role in generating specific impacts: 'I contend that the study of social movement mobilization must account for the cultural opportunities available to movements, the impact of the opposing movement, and, in particular, the perception or interpretation of events or practices that make them opportunities' (p. 45).

Besides frames and cultural opportunities, another element which Dugan brings to the fore is that of collective identity and the way it was differently built around the issues of leadership, shared belief, cooperative strategy and conflict. Perhaps one of the most striking features of this book is the way conflict is portrayed. In fact, Dugan suggests that it was the pervasive conflict between assimilationist or mainstream activism and radical or queer activism in the LGB movement which hindered a unified campaign, failed in providing evidence of discrimination and led to further division and detachment among the LGB friendly electorate. Conversely, the Christian Right was successful in taking advantage of their opponents' vulnerability, gluing Issue 3 proponents around common beliefs, leadership and straightforward buzzwords, which in turn resulted in the approval of Issue 3.

In general, this book is an important contribution to the study of collective action and contentious politics, using a stimulating language and content, and pointing to new possible directions for researching social movements. Among the most important findings is the strategic use of the same civil rights master frame with opposite purposes, the interpretation of political opportunities as cultural opportunities, the importance of adaptive strategies - namely 'responsive framing and retooling of messages' (p. 118) - and the recognition of the role of social movements in influencing other movements' decisions and outcomes.

Ana Cristina Santos

University of Leeds, UK

Centre for Social Studies, University of Coimbra, Portugal 